\title{
Smoking Status
}

National Cancer Institute

\section{Source}

National Cancer Institute. Smoking Status. NCI Thesaurus. Code C19796.

An indication of a person's current tobacco and nicotine consumption as well as some indication of smoking history. 